\title{
INDIVIDUAL AND CORPORATE SOCIAL RESPONSIBILITY ${ }^{1}$
}

\author{
Roland Bénabou ${ }^{2} \quad$ and Jean Tirole ${ }^{3}$
}

November 11, 2009

${ }^{1}$ This paper formed the basis for the Coase lecture, delivered by Jean Tirole at the London School of Economics on February 19, 2009. We are grateful to Francesco Caselli and Augustin Landier for valuable comments. Bénabou gratefully acknowledges support from the Canadian Institute for Advanced research.

${ }^{2}$ Princeton University. rbenabou@princeton.edu

${ }^{3}$ Toulouse School of Economics. tirole@cict.fr 


\begin{abstract}
Society's demands for individual and corporate social responsibility as an alternative response to market and distributive failures are becoming increasingly prominent. We first draw on recent developments in the "psychology and economics" of prosocial behavior to shed light on this trend, which reflects a complex interplay of genuine altruism, social or self image concerns, and material incentives. We then link individual concerns to corporate social responsibility, contrasting three possible understandings of the term: the adoption of a more long-term perspective by firms, the delegated exercise of prosocial behavior on behalf of stakeholders, and insider-initiated corporate philanthropy. For both individuals and firms we discuss the benefits, costs and limits of socially responsible behavior as a means to further societal goals.
\end{abstract}

Keywords: corporate social responsibility, socially responsible investment, image concerns, shareholder value

JEL numbers: D64, D78, H41, L31. 


\section{Introduction}

Economists' view of how society should be organized has traditionally rested on two pillars. The invisible hand of the market described in Adam Smith harnesses consumers' and corporations' pursuit of self-interest to the pursuit of efficiency. The state corrects market failures whenever externalities stand in the way of efficiency and redistributes income and wealth, as the income and wealth distribution generated by markets has no reason to fit society's moral standards. In industrialized democracies, much of the political spectrum has converged on this division of labor, albeit with some sharp divergences of opinion as to the relative roles of the market and the state. ${ }^{1}$

Textbook economics has thus long embraced the shareholder-value approach, which posits that firms should be controlled by profit-maximizing shareholders while other stakeholders are protected by contracts and regulation. Stakeholders' insulation from managerial decisions operates through fixed nominal claims (wages and severance pay, fixed debt repayment combined with priority and collateral, etc.) and exit options associated to general training, flexible labor markets and short-term debt maturities. The state is supposed to step in only when satisfactory contracting solutions would involve high transaction costs or require more symmetry in the information held by the parties; cases in point include environmental taxation, antitrust, prudential regulation, and the regulation of network industries. The state also controls redistributive taxation. In a nutshell, following Pigou (1920), the state, and not citizens or firms, is in charge of correcting market failures and income or wealth inequality.

Yet, society's and lawmakers' demands for individual and corporate social responsibility as an alternative response to market and redistributive failures have recently become more prominent. $^{2}$ To be sure, calls for people to contribute time and money to good causes have existed throughout history and in all societies, from Antiquity ${ }^{3}$ to, say, 18th century Quakers' and Mennonites' refusal to invest in weapons and slavery. But the movement is gaining momentum, especially with the empowerment of civil society (NGOs) and the equitable-trade / responsible-investment movement. A variety of factors probably combine to account for this trend: (i) social responsibility is likely to be a normal good; (ii) information about companies' practices throughout the world has become much more accessible and quick to travel; (iii) the scope of environmental and social externalities exerted by multinationals in less developed, more laxly regulated countries is likely

\footnotetext{
${ }^{1}$ On this last point, see Bénabou and Tirole (2006b) and Bénabou (2008a).

${ }^{2}$ For instance, according to data from the Social Investment Forum Report (2007), cited in Andries (2008), the value of assets under management in the US that fall into the SRI category grew at annual rates of about $12 \%$ over 1995-2005 and 18\% over 2005-2007; by the end of 2007, these SRI assets accounted for $11 \%$ of total assets under professional management. Other signs of the same trend include the proliferation of fair- trade products, carbon offsets and newly-created positions such as Corporate Sustainability Officer in many large companies.

${ }^{3}$ See, e.g., Avlonas (2009) on ancient Greece.
} 
to have expanded in pace with globalization; (iv) the long-run cost of atmospheric pollution (e.g., global warming), or at least the public's awareness of it, has risen significantly.

Responding to such demands, business leaders, governments and academics are now also emphasizing the notion of corporate social responsibility (CSR). A standard definition of CSR is that it is about sacrificing profits in the social interest. For there to be a sacrifice, the firm must go beyond its legal and contractual obligations, on a voluntary basis. CSR thereby embraces a wide range of behaviors, such as being employee friendly, environment friendly, mindful of ethics, respectful of communities where the firm's plants are located, and even investor friendly. Sometimes, the call for duty extends beyond the corporation's immediate realm and includes supporting the arts, universities and other good causes.

Why do citizens and corporations empower themselves and substitute for elected government? A first and clearly relevant motivation is that government may itself fail. Government failures have multiple origins:

- Capture by lobbies and other interest groups. Governments under influence may fail to correct externalities as Pigovian principles would recommend, or bend to wealthy constituents' opposition to redistributive policies.

- Territoriality of jurisdiction. For instance, one cannot rule against child labor in a distant, sovereign country, and an outright import ban may be infeasible due to international trade agreements or other policy constraints. Consumer boycotts and investor activism then become the outlet through which citizens can express their opposition to these practices.

- A combination of inefficiency, high transaction costs, poor information and high delivery cost. The state thus has a comparative disadvantage in policing minor nuisances such as a lack of respect for employees or conspicuous consumption by executives, or in directing resources to very local needs. "Appropriate" behaviors in such contexts are instead enforced through the pressure of social norms and popular demands that firms be socially responsible. ${ }^{4}$

A second important motivation is that economic agents may want to promote values that are not shared by lawmakers. Because preferences are heterogenous, it is inevitable that some consumers, investors or workers' values will not be fully reflected in policy. They, or organized groups acting on their behalf, will then become activists. ${ }^{5}$

\footnotetext{
${ }^{4}$ See Shavell (2002) and Besley and Ghatak (2007). For example, the latter authors emphasize that for CSR to be socially beneficial, corporations must be more efficient than the government at producing public goods.

${ }^{5}$ In his review of what economics has to contribute to our understanding of CSR, Kitzmueller (2008) notes that if ethical consumers are a minority (majority), the government may under (over) regulate.
} 
Despite its growing importance, little is known about the economics of individual and corporate social responsibility. This paper draws on recent developments in psychology and behavioral economics to shed some light on the new trend, its future and its limits. It considers the benefits and costs of socially responsible behavior (SRB), and asks whether it is a viable model for the achievements of social goals. This work is still in the early stage and the paper can thus primarily help us organize our thinking on these issues. Subject to this caveat, the take-home message is that SRB holds real promise, provided we understand its motivations and limitations.

The paper is organized as follows. Section 2 discusses individual social responsibility, and Section 3 corporate social responsibility. Section 4 concludes with a summary and some open questions.

\section{Individual social responsibility}

Many people give to charities, invest in socially responsible funds, consume green products, supply their blood, or give their time and sometimes even their life for good causes. Such prosocial behaviors obey a complex mix of interdependent motivations. First, they are driven by genuine, intrinsic altruism: to varying degrees, we all aspire to do good and help. Second, material incentives may come into play: we are more likely to give to charities if contributions are tax deductible. Third, we are also driven by social- and self-esteem concerns. Our conduct defines what kind of person we are, in the eyes of others and, no less importantly, in our own. The main focus of this section will be to identify the bright and dark sides of such image concerns, how these interact with intrinsic motivation and extrinsic incentives, and the implications for public policy.

\subsection{Some evidence on image concerns}

Let us make the case, if needed, that prosocial behaviors cannot be understood if one ignores image concerns, starting with some examples in which social image plays a key role.

Anonymous donations are widely considered to be most admirable, and yet they typically represent at most $1 \%$ of the total number (Glazer and Konrad, 1996). The implied conclusion that buying social prestige is part of the incentive to engage in prosocial behavior is confirmed by several recent experiments.

A blood donation experiment in Italy awarded bronze, silver and gold "medals" for how often people donated blood (Lacetera and Macis 2008). Such rankings had a significant effect, but only when the results were published in newspapers. Another interesting finding of the study, which concurs with similar ones for philanthropy in the arts and education in several countries, is that people tend to "bunch" right above the cutoffs for each category (e.g., Buraschi and Cornelli, 
2002). In the absence of image concerns, contributions would be much more evenly spread.

A similar conclusion emerges from the introduction of mail ballots in some cantons in Switzerland (Funk 2008). The ability to vote by mail reduces the cost of voting, so according to standard price theory it should increase turnout. It actually did not increase voting on average, and even reduced participations in small communities. This supports the idea that demonstrating one's good citizenship to neighbors and friends is an important part of the motivation for voting, especially in small towns and villages where this behavior is more observable than in large cities. By making no-shows less visible (creating a potential excuse), mail ballots then tend to depress turnout in such communities. A similar effect was recently demonstrated in a field experiment on door-to-door charitable solicitations by DellaVigna et al. (2009). When households were informed in advanced (by a flyer on their door-knob) of the exact time when the solicitor would come by, the fraction opening the door declined by 10 to 25 percent, and when the flyer allowed checking a 'Do Not Disturb' box, giving was 30 percent lower.

Another interesting experiment focuses on volunteer firemen in Vermont (Carpenter and Myers 2007). The authors first measured subjects altruism by their willingness to share in an experimental dictator game, then related this measure to time spent in various fire-volunteering activities. Altruism was found to make a difference for participation in training, which has a low public visibility, but not for call response, where visibility is much higher. Conversely, having on one's car "vanity" license plates of a type typically associated to rescue activities (the Maltese cross) was associated with the reverse pattern of time allocation.

Self-image concerns are also important motivators: we act prosocially in part to reassure ourselves that we are good people. ${ }^{6}$ While this idea is familiar and intuitive, it is most cleanly demonstrated in laboratory experiments, where anonymity (even to the experimenter, under the double-blind procedure) ensures that social-image concerns are irrelevant.

In the standard dictator-game experiment, for instance, many subjects are willing to make at least a small sacrifice in their own payoff to benefit others. This is prima facie evidence of the existence of altruistic, other-regarding preferences. The real picture is more complex, however, as a clever experiment by Dana, Weber and Kuang (2007) demonstrates. As these authors show, when given the opportunity not to know whether their actions actually hurt others, many people take advantage of this "moral wriggle room" to make selfish choices. Their main experiment contrasts two variants of a dictator-like game, with anonymous players. In a first, "known" condition, subjects choose between a selfish option $A$ that delivers 6 to them and 1 to someone else, and a fair option $B$ delivering 5 to each. In conformity with many previous such experiments

\footnotetext{
${ }^{6}$ See Bénabou and Tirole (2007).
} 
about three quarters of subjects choose $B$. In a second, "uncertain" condition, subjects can again choose either 6 (option $A$ ) or 5 (option $B$ ) for themselves, but they do not know what the other player will receive in each case. They are told only there are two versions of the game, drawn at random with equal probabilities, which they could be playing. In version 1 , the payoffs to $A$ and $B$ are as above, namely $(6,1)$ and $(5,5)$, creating the same tradeoff between material gain and generosity. In version 2 , there is no tradeoff: $A$ leads to $(6,5)$ and $B$ to only $(5,1)$. Subjects are also given the opportunity to find out, immediately and at no cost, which of the two versions of the game they have randomly drawn and will be playing. According to standard decision theory, truly generous individuals should strictly prefer to learn the state of nature, as this would allow them to choose $B$ in state 1 and $A$ in state 2 . Yet half of the subjects choose not to know and proceed to select option $A$, presumably seizing the (false) excuse that they may not be hurting the other. This behavior, akin to changing sidewalk not to pass by a beggar, shows how subtle we are when we play games with ourselves. We understand (probably not even consciously) that our memory is imperfect and that creating a "cloud of smoke" around whether one was actually selfish can thus provide a self-excuse for our pursuing our own interests.

Other experiments, sometimes involving even more transparent self-deception, lead to similar results and conclusions. Dana et al. (2006) thus show that many people who would voluntarily share $\$ 10$ with an anonymous other in a dictator game prefer to just take $\$ 9$ for themselves and not face that choice. In a related vein, Hamman et al. (2009) show that many subjects who would otherwise behave generously in a dictator game will, given the opportunity, delegate the sharing decision to a third party who has a acquired a reputation for being biased in favor of delegating principals. Put differently, economic agents are eager to delegate the "dirty work" that they would not want to do themselves; somehow, not directly choosing the selfish action seems to exonerate them from what would be the logical damage to self-esteem.

All these experiments point at the idea that self-signals play an important role. Accordingly, one would expect the cost to self-esteem incurred from selfish actions to be magnified when these become more salient, or memorable. Indeed, Mazar et al. (2008) find that subjects who can cheat (for money) on a task without any risk of detection, cheat less when they are first made to read the Ten Commandments or their university's honor code. Such reminders of moral precepts should, according to the standard economic model, be irrelevant. In fact, by making transgression of these precepts more salient, they reduce the ambiguity on which self-deception relies, inducing more honest behavior. 


\section{The Graffiti of the Philanthropic Class}
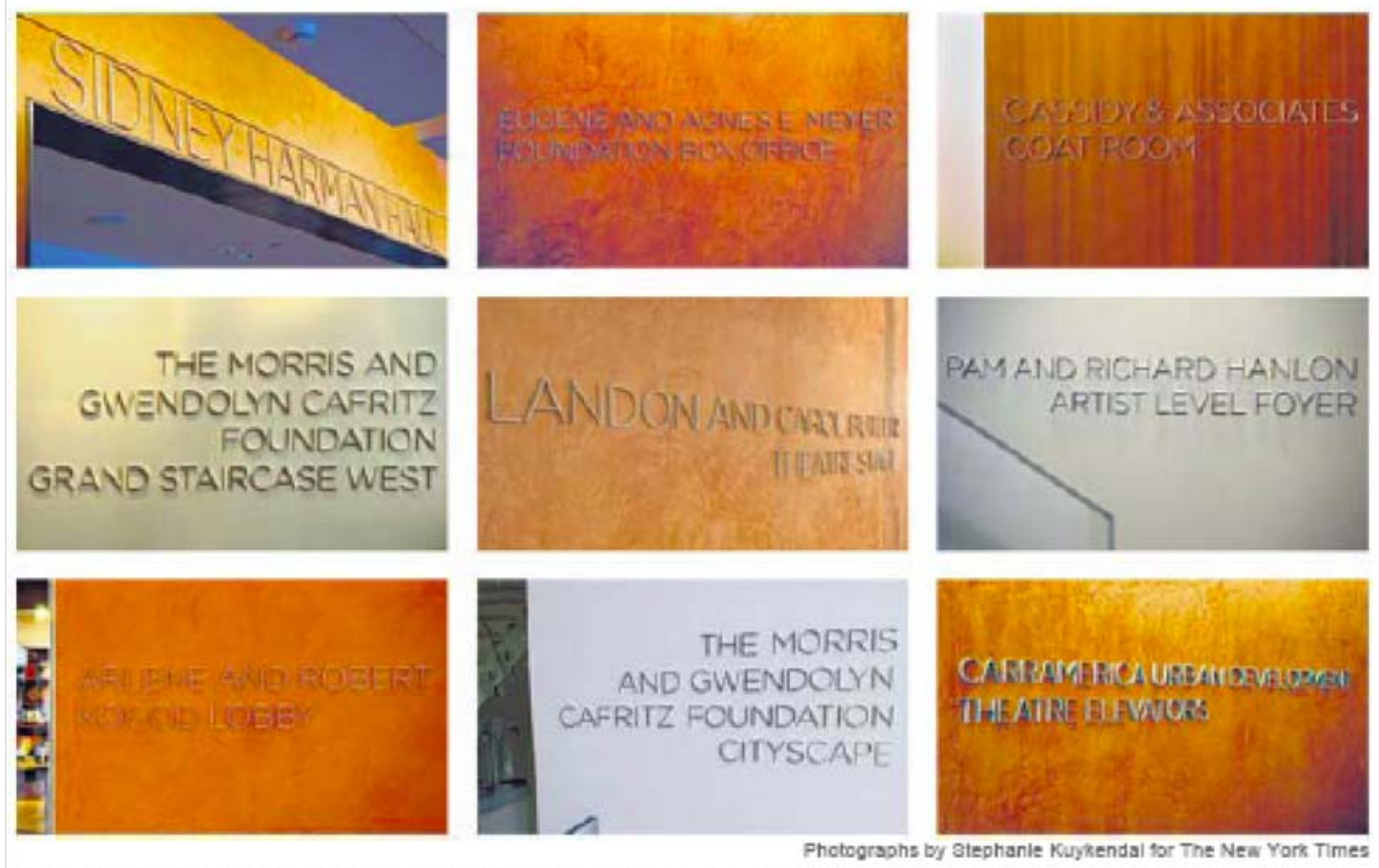

At the Shakespeare Theater Company's new home in Washington, pretty much everything, including staircases and the coat room, has been named after somebody.

Figure 1: Source: Isherwood (2007)

\subsection{The bright side of image concerns}

From a policy perspective, the importance of image concerns offers an opportunity, as they can cheaply be levered to increase prosocial behavior. There are numerous examples of such strategies:

- On the good-behavior side (trying to leverage honor seeking), contributors to public goods receive public praise, medals, T-shirts, "best of" awards, and so forth. Publicity is amply given for good deeds, or even bought outright (something we will come back to), as exemplified by Figure 1.

- On the bad-behavior side (trying to leverage stigma avoidance), various modern versions of the pillory are gaining popularity, such as internet "walls of shame" for DWI arrests or non-payment of child support, televised arrests, and so forth.

This discussion points to a potential role of socially responsible investment, green products and other "good-citizenship" modes of consumption and saving. When self-views are involved, we are 
very good at deception, inattention and rationalization. The main virtue of socially responsible products and their widespread diffusion is that they provide frequent reminders of things we prefer not to think about, such as poverty, injustice, or the environmental impact of our consumptions. ${ }^{7}$

\subsection{Importance of image concerns: the darker side}

There are four potential elements on the "dark side" of exploiting social and self-image motives to spur prosocial behavior - all of which become quickly apparent when reflecting upon the nature and content of Figure 1.

(a) The efficacy of publicizing people's good and bad deeds is, in a sense, self-limiting. As publicity is scaled up, people discount the meaning of prosocial acts, attributing their motivation more to image-seeking and less to altruism. This form of "overjustification effect" implies a partial crowding out of the incentive provided by publicity (see Bénabou and Tirole 2006a for a formal analysis). The implication is that the more "advertised" socially responsible investments (SRI's) are, the more they will be discounted.

(b) Another cost relates to individuals' choice of signals. Giving is heavily distorted toward the more visible or memorable targets: Americans, for instance, donate substantial amounts to Harvard, Yale, Princeton and other well-known alma maters, but far less to primary and secondary schools. Similarly, giving to concert halls and museums has much greater "glamor" and networking value than giving to the poor. ${ }^{8}$ A similar point applies to green investment by households: as Ariely et al. (2009) note, buying a hybrid car or installing solar panels buys more social prestige than insulating one's house or buying an energy-efficient furnace. While the latter investments are in fact more ecologically virtuous, they are also invisible to others, and after a while even to oneself.

(c) The quest for social prestige or the enhancement of self-image is, in itself, a zero-sum game -in the parlance of sociologists, a positional good. The buyer of a hybrid car feels and looks better, but makes his neighbors (both buyers and non-buyers of hybrid cars) feel and look worse a "reputation stealing" externality. In the limit, when everyone behaves in a socially responsible way, no one gets credit for it.

\footnotetext{
${ }^{7}$ Those reminders operate not only at the individual's level, but also that of groups. Within firms or their boards, in particular, SRI advocates can thus act as safeguards against overoptimistic "groupthink", systematically asking management to present worst-case or disaster scenarios, appointing devil's advocates, protecting whistle-blowers, and so on. For more on groupthink and its prevention, see Bénabou (2008b).

${ }^{8}$ At least domestically; giving to poor countries is somewhat different, in part because of different attributions made for the causes of their poverty (see Bénabou and Tirole 2006b), and in part because such giving has much greater visibility, as it takes place on a "global" stage.
} 


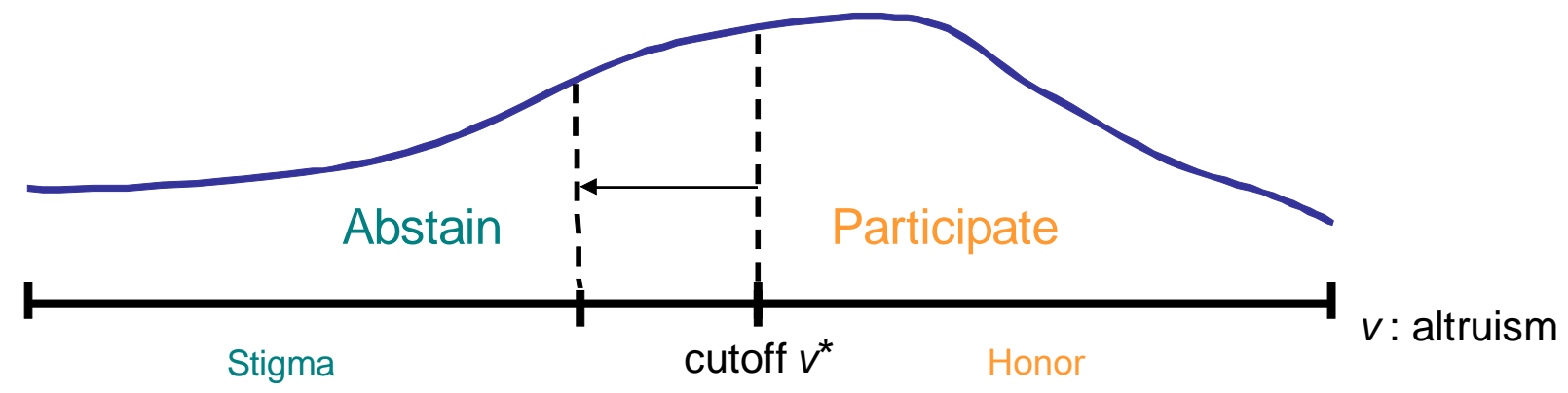

Figure 2: Honor and stigma. Source: Bénabou and Tirole (2006a)

Figure 2 depicts what happens when participation in a prosocial activity increases. Individuals with intrinsic motivation (altruism) above some threshold receive the honor attached to participation, while those below it abstain and suffer stigma. When participation increases, the honor involved decreases (prosocial behavior becomes more common) and the stigma for not participating increasing (only the "very bad apples" do so).Evidence that the quest for social prestige is a zero-sum game (or at least is perceived to be) is provided by Monin (2007) and Monin et al. (2008). In a series of experiments, these authors document a frequent backlash against "moral rebels" such as vegetarians or subjects who refuse to play along in an ethically questionable scenario -people who in principle should restore our faith in human nature, but in practice make us feel morally inadequate. Outside the laboratory, moreover, such adverse reactions to "do-gooders" are socially costly: they will be ostracized, threatened or harmed, creating a welfare loss.

(d) Our moral standards are challenged along multiple dimensions and in repeated instances. Good behavior in one context may "justify" a more mediocre one in another, and people who have recently "done good" in one dimension may feel immunized against negative (social or self) inferences, and thus later on act less morally constrained. Monin and Miller (2001) document this "moral credentializing" in experiments on gender or ethnic stereotyping: subjects who were previously given an opportunity to make statements "demonstrating" a lack of bias against women or minorities are, subsequently, more likely to later make a (hypothetical) decision or express an opinion that conforms to negative stereotypes about the group in question.

\subsection{Material incentives, image concerns, and policy}

Economists' standard "internalization" recommendation with respect to externalities dates back at least to Pigou (1920): taxes on pollution or other socially harmful behaviors should equal their net social cost; subsidies for prosocial behaviors should be set at their net social benefit. A more 
psychologically informed approach to public economics does not invalidate, but qualifies this basic principle, which underlies so much of public policy. Indeed, there is a second externality involved, arising from the "reputation stealing" effect discussed above. The socially optimal incentive rate should therefore be lower than the usual Pigovian level: it must subtract from the standard externality cost the image value implicitly "bought" by the individual or firm.

\section{(a) Amending Pigou}

This simple policy prescription raises several issues. First, image values may not always be easy to measure, although there are implicit markets for items such as a named building, a plaque or university chair. Second, and relatedly, one would want to know when the correction can be significant and when it is likely to be negligible. In this respect, we have already seen that image concerns are influenced by visibility: efficient furnaces may need to be subsidized more than hybrid cars.

Perhaps more subtly, image concerns depend endogenously on the prevalence of the behavior in question. Provided that the distribution of altruism in the population is unimodal (as in Figure 2), one can show (see Bénabou and Tirole 2010) that, for a given social cost of the externality, the optimal subsidy varies non-monotonically with the proportion of people choosing the socially responsible option: see Figure 3, which depicts this correction to Pigovian taxation. Intuitively, "admirable" acts - those which very few individuals in society perform (or would perform without considerable incentivization) carry substantial social prestige, and should therefore command only modest material incentives. At the other end, "respectable" acts - those which "any decent person" would engage in (absent exceptional constraints or inducements)- are such that failing to perform them entails to enormous stigma; so here again, material incentives should be low. "Modal acts", which are neither admirable nor merely respectable, are those for which Pigovian precepts apply best and extrinsic incentives should be strongest.

(b) Crowding out and the overjustification effect

The observation that the image value of different behaviors is endogenous (determined together with the equilibrium behavior of the whole population) has another important implication: the level of material incentives will affect this attribution problem, and therefore the (self) reputational return to prosocial acts. This is illustrated in Figure 4, drawn from Bénabou and Tirole (2006a)

This figure depicts a population's average contribution $\bar{a}$ to a public good (say, donating blood) or conformity to some socially desirable behavior, as the material reward $y$ for doing so (or, conversely, the penalty for failing to) increases. ${ }^{9}$ In the absence of image concerns, aggre-

\footnotetext{
${ }^{9}$ The specification of preferences underlying the figure is

$$
U=\left(v_{a}+v_{y} y\right) a+\mu_{a} E\left[v_{a} \mid a, y\right]-C(a),
$$
}




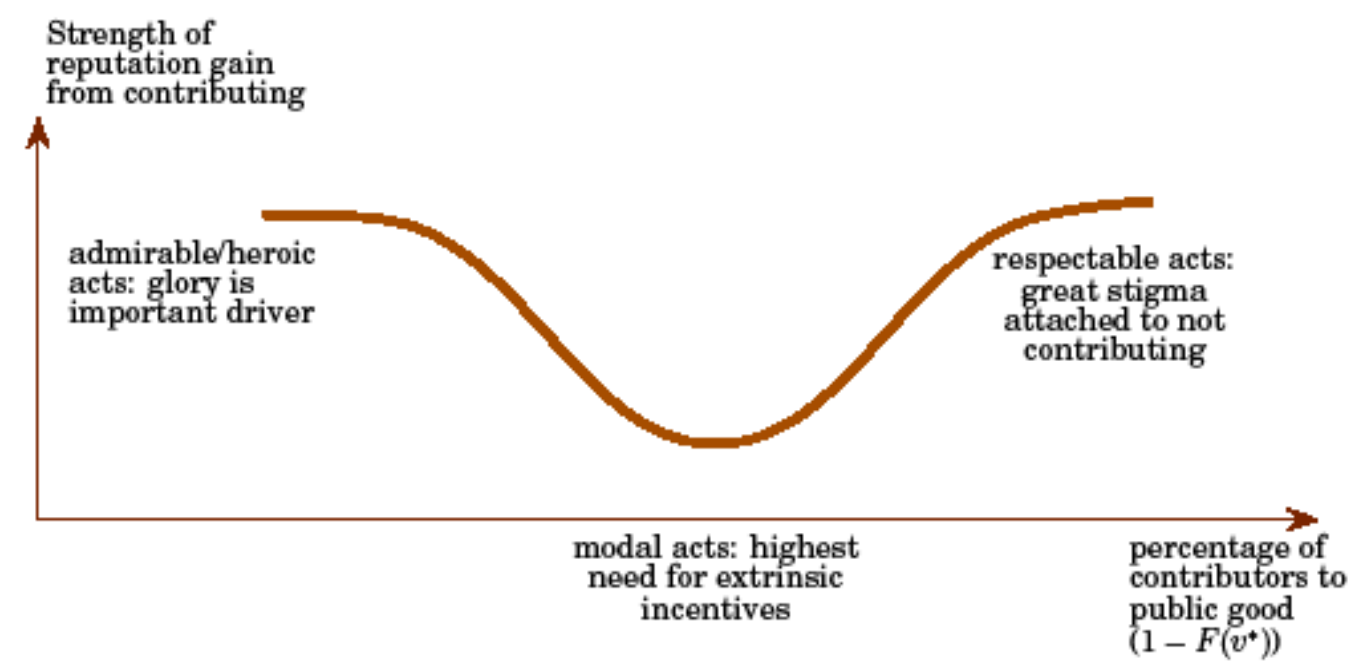

Figure 3: Correcting Pigou's rule. Source: Bénabou and Tirole (2010)

gate behavior conforms the representation of Homo Economicus in Econ 101: a higher reward elicits increased supply. As image become more important, an unusual phenomenon also occurs: over some interval, the supply response to incentives flattens out and, eventually, becomes downward-sloping. This violation of basic price theory results from what psychologists call the overjustification effect, and economists would call a signal-extraction problem. When there is no or little reward, a prosocial act is interpreted as genuine altruism. As material incentives become more substantial, the "meaning" of the act changes: it becomes more difficult to know to what extent it is motivated by altruism or by greed (since people also differ along both dimensions). The signaling value of prosocial behavior thus weakens, offsetting or even reversing the direct effect of higher incentive. Of course, when rewards become sufficiently large, supply eventually recovers its standard upward-sloping nature, but such levels of payments could be very costly.

Figure 4 and the more general analysis underlying it have other testable implications besides the possibility of crowding out. First, prosocial contributions increase when their visibility, and therefore their impact on social esteem, increase. Second, the power of incentives is weaker (or even be negative) when image concerns are large. Ariely, Bracha and Meier (2009) provide empirical validations of these predictions. In their experiments, subjects performed tasks to earn

where $v_{a}$ and $v_{y}$ parametrize an individual's degree of altruism and marginal utility of income; $a$ is his level of contribution, $C(a)$ the associated cost and $y$ the per-unit incentive rate; finally, $E\left[v_{a} \mid a, y\right]$ is the best estimate of $v_{a}$ conditional on the chosen action and its reward, and $\mu_{a}$ the intensity of the image concern, common to all agents for for simplicity. The joint distribution of $v_{a}$ and $v_{y}$ is taken to be Gaussian and $C(a)$ is quadratic. The curves shown in Figure 4 correspond to different values of $\mu_{a}$. 


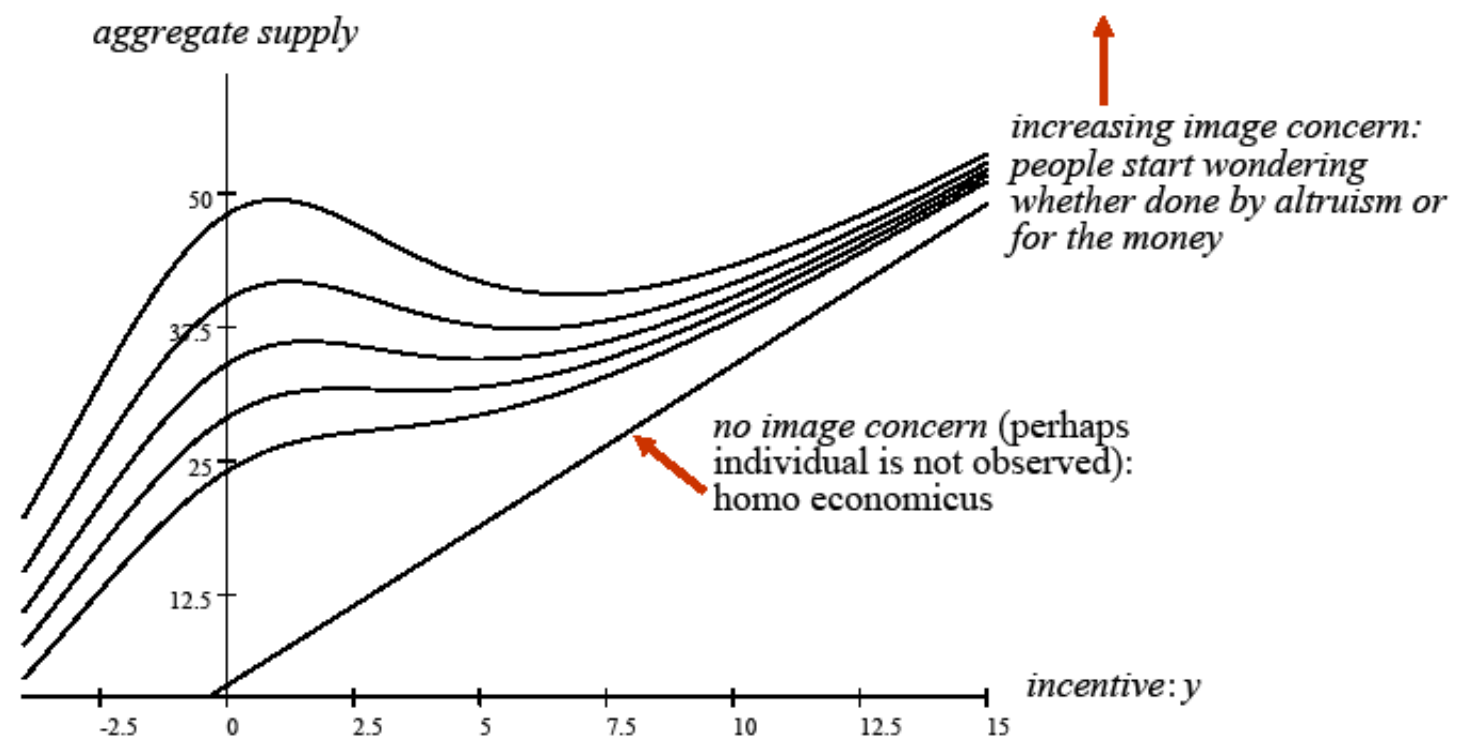

Figure 4: The overjustification effect. Source: Bénabou and Tirole (2006a).

money for charitable causes under two conditions. In a "private" condition, only the individual observes his effort and amount earned (only his self-image can be at stake). In the "public" condition all subjects, and possibly some other peers, observe each person's choices (so both selfand social-image are involved). The first observation, which corroborates many earlier findings (e.g., Freeman 1997), is that contributions are larger when they are public. The second one is more striking: in conformity with the theoretical prediction, the impact of material incentives weakens considerably (or even reverses) when they are public. Moreover, this change in slope occurs only when the task is performed for a good cause: it is absent when it is known that subjects are simply earning money for themselves, or for an organization most observers disapprove of. These results are consistent with the idea that subjects in the public condition seem worried that the presence of rewards may cause their prosocial behavior to be attributed to greed more than to altruism. Moving beyond the laboratory, such findings provide a further rationale for subsidizing efficient furnaces more than hybrid cars.

As we noted earlier, a second form of the overjustification effect arises from the fact that also people differ in the intensity of their image concerns. Some are literally obsessed with social esteem, while others care about it much less. When good deeds are very visible (by their nature of by policy design), they will then be "discounted" as being likely to reflect a strong desire to "buy" admiration. This discount, in turn, will dampen the signaling incentive to act prosocially, 
and this even when image seeking is not frowned upon per se -it just reduces the attribution of good behavior to genuine altruism. This effect never fully crowds out the impact of an increase in the publicity of actions (medals, citations, wall of shame, etc.), but can substantially dampen it. $^{10}$

Such "concerns about not looking image-concerned" resonate, as they are present in our everyday life. Most people hesitate to boast about their good actions and would much rather have third parties advertise these acts for them. This follows naturally from the logic of inference: someone who brags about his good deeds signals that he is image-concerned and creates a suspicion about the extent of his true altruism.

\section{Corporate social responsibility}

Corporate social responsibility (CSR) is somewhat of a "catch-all" phrase for an array of different concepts. An analysis of CSR must therefore clarify its exact meaning, and in particular the presumed impact of CSR on the cost of capital. Some CSR advocates argue that there is a business case for good corporate behavior, while others discuss it in terms of sacrificing some profit in the quest for the social good. This section is, accordingly, divided into two parts. The first discusses three alternative visions of CSR. The second discusses the challenges and opportunities faced by the CSR movement.

\subsection{Three views on CSR}

(a) Vision 1: "Win-win" ("doing well by doing good")

According to some advocates of CSR, being a good corporate citizen can also make a firm more profitable. Since firms presumably have no interest in simultaneously reducing profits and harming society (damaging the environment, hurting workers or consumers), for such a claim to be more than management consultants' promise of a "free lunch" it requires elaboration, as well as supporting evidence. There are two ways in which it could be reasonably interpreted, corresponding respectively to visions 1 and 2 below.

The first one involves the existence of limits to governance and managers' temporal horizons. As a large literature in finance has emphasized, firms often suffer from a short-term bias. This may be due to poorly structured managerial incentives, but such biases can also result from well-designed schemes. First, monetary incentives often put more weight on short-term than on long-term performance. Although the recent crisis has brought more widespread recognition of the hazards which short-term-oriented compensation schemes create for corporations and society, some dependence on current or recent firm performance is inevitable. Second, decisions by boards

\footnotetext{
${ }^{10}$ See Bénabou and Tirole (2006a).
} 
and shareholders of whether to keep current management, change it or alter the scope of its activities are also necessarily based in part on recent observation (even if some of the long-term impact of managers' actions may filter through long-term indicators such as the stock price. ${ }^{11}$ ). Thus, career concerns also generate some short-term biases.

In practice, short-termism often implies both an intertemporal loss of profit and an externality on stakeholders. That is, managers take decisions that increase short-term profit, but reduce shareholder value and hurt workers or other constituencies. For example, a firm may renege on an implicit contract with its labor or suppliers so as to reduce costs, thereby damaging goodwill -making it more difficult to attract motivated workers in the future, or to induce suppliers to make relationship-specific investments (e.g., Krueger and Mas 2004). Alternatively, a firm could economize on safety or pollution control; this also increases short-run profits, but creates contingent liabilities down the road: risk of future lawsuits, consumer boycotts and environmental cleanup costs. In such cases, the "win-win" argument makes clear sense.

The upshot is that, in this first vision, CSR is about taking a long-term perspective to maximizing (intertemporal) profits. This suggests that socially responsible investors should position themselves as long-term investors who monitor management and exert voice to correct shorttermism.

In the same vein, but with much more ambiguous welfare consequences, "strategic CSR" (to use a term coined by Baron 2001) consists in taking a socially responsible stance in order to strengthen one's market position and thereby increase long-term profits. For instance, CSR could be a means of placating regulators and public opinion to avoid strict supervision in the future, or to attempt raising rivals' cost by encouraging environmental, labor or safety regulations that will particularly handicap competitors.

(b) Vision 2: Delegated philanthropy (the firm as a channel for the expression of citizen values)

For the reasons discussed in Section 2, some stakeholders (investors, customers, employees) are often willing to sacrifice money (yield, purchasing power and wage, respectively) so as to further social goals. Put differently, stakeholders have some demand for corporations to engage in philanthropy on their behalf. The corresponding CSR profit sacrifice is then passed through to stakeholders at their demand.

Note that one needs to explain why people would want corporations to do good on their behalf, rather than doing it on their own or through charitable organizations, churches, etc. Information and transaction costs are clearly important here. In theory, consumers could send money to directly supplement the income of workers in the coffee plantations supplying Starbucks. But

\footnotetext{
${ }^{11}$ On this point, see e.g., Holmström and Tirole (1993).
} 
they would have to be informed about the occurrence of individual trades and contracts and their financial transfers would involve enormous transaction costs. Somehow, philanthropy must thus be delegated. It could perhaps be entrusted to some charitable organization, but transaction costs are still likely to be much lower if delegation goes through the corporation, which already is involved in a financial relationship with the workers.

Another argument for asking corporations to behave pro-socially is that the desired actions are often not about transferring income to less-favored populations, but about refraining from specific behaviors, such as polluting the environment; here there is no substitute for asking the firm to behave well when the state does not impose constraining regulations. A related case is when a firm draws on its technical expertise or exploits complementarities to deliver goods and services to those in need more efficiently than the governments or other philanthropic "intermediaries" could. Examples include a giant supermarket chain organizing relief convoys to a zone hit by a hurricane, or a large water-treatment utility setting up a program of digging water wells for poor, remote villages in a developing country.

Many examples come to mind: Starbucks increases its demand by buying fair trade coffee and tea. Other firms advertise heavily that their clothing is made from organic cotton, or the product of fair trade. Some corporations provide incentives for employee engagement in community service, thereby boosting public relations with the local communities and attracting motivated employees (Besley and Ghatak 2005, Brekke and Nyborg 2008). The view that corporations engage in socially responsible behavior (SRB) on behalf of stakeholders is also supported by the observation that "sin stocks" (tobacco, alcohol, casinos) exhibit higher returns (Hong and Kacperczyk 2009). ${ }^{12}$ On the other hand, and as we will later discuss, other empirical research fails to demonstrate a link between CSR behavior and a lack of profitability.

The idea that firms exercising CSR are responding to consumer and investor demand that they "do good" on their behalf is consistent with the greater prevalence of such practices among firms that are large, profitable, produce final goods and are scrutinized by NGOs. Visibility with respect to stakeholders demanding SRB thus incentivizes firms to engage in such behavior. ${ }^{13}$

As with individuals, the image concerns of corporations also have their darker side, taking here the form of "greenwash: disseminating a misleading picture of environmental friendliness or other SRB, or one that is accurate in some dimensions but serves to obscure less savory ones. Thus, Enron was a huge corporate giver, particularly to the Houston area, and one of the most impressive "glossy brochures" documenting the multiple facets of a firm's CSR benevolence is the

\footnotetext{
${ }^{12}$ A similar conclusion is reached by Geczy et al (2005).

${ }^{13}$ Of course, NGO scrutiny is itself endogenous.
} 
one issued in 2007 by AIG. ${ }^{14}$

Vision 2 of CSR does not raise any specific corporate governance issue: management caters to demand and maximizes profit. As with the long-term perspective, profit maximization and CRS are consistent.

(c) Vision 3: Insider-initiated corporate philanthropy

In this interpretation of CSR, corporate prosocial behavior is (at least in part) not motivated by stakeholders' demands or willingness to sacrifice money for a good cause, but rather reflects management's or the board members' own desires to engage in philanthropy. For instance, corporations often give to charities on the boards of which their executives or own board members sit, or to institutions (concert halls, opera houses, museums) and causes (e.g., political thinktanks) which their top management favors. ${ }^{15}$ Profit is then typically not maximized.

This type of philanthropy has come under attack from both the right and left sides of the political spectrum. In a well-known piece, Milton Friedman (1970) wrote in essence that corporations should not do charity with others' money. Rather, managers and directors should employ their own wealth to this purpose. On the other side of the aisle, Robert Reich has argued that there is no way to ensure that private money will go to the "right" causes and that firms should not substitute for the state (meaning, presumably, that elections provide the legitimacy to define what is "right"). In practice, the state restricts the set of potential recipients of corporate generosity by deciding which institutions are eligible for tax-deductible contributions. So, while it has very imperfect control over the allocation, it at least keeps control over the identity of recipients.

Unlike the citizen-delegation view, the view of corporate philanthropy as management-initiated raises substantial corporate governance issues. Indeed, if investors simply demand the highest possible return (implying no tolerance for SRB if they do not benefit from it), managers and the board must be somewhat entrenched in order to be able to practice corporate philanthropy on a large scale (Cespa and Cestone 2007). The notion of a broader mission of management than just maximizing shareholder value necessarily involves some cost to corporations, making it more difficult for them to raise funds from investors. ${ }^{16}$ It may also weaken managerial accountability by creating multiple objectives and performance criteria; at the extreme, too many missions amount to no mission at all (Dewatripont et al. 1999).

\footnotetext{
${ }^{14}$ See American International Group, Inc. (2007), p. 4-5.

${ }^{15}$ Among other instances, Jennings (2006) relates that "from 1992 to 2002, while Dennis Koslowski served as CEO, Tyco gave 35 million to charities designated by Mr. Koslowski... Mr. Koslowski served on the board of the Whitney Museum of American Art, and, as a result Tyco donated 4.5 million to the travelling museum shows that Whitney sponsored."

${ }^{16} \mathrm{It}$ is interesting to note that this notion is more popular in civil-law countries, which put more emphasis on stakeholder participation in governance and a broader duty of firms to society than in common-law countries, where shareholder value has primacy.
} 
In practice, the dividing line between the different notions of CSR -long-term perspective (vision 1, delegated philanthropy (vision 2) and profit-sacrificing insiders' philanthropy (vision 3) may be elusive. Consider, for instance, the increasingly popular practices of nominating someone with a good external reputation as a Corporate Sustainability Officer, or of turning to reputable NGOs for advice and help. Do firms hire a Corporate Sustainability Officer to serve as an advocate against short-termism - a kind of environmental risk manager, in effect- within the firm? Or is this executive meant to be a voice for costly prosocial behavior demanded by stakeholders? Similarly, consider the introduction of monetary incentives based on environmental performance. Are they meant, say, to encourage divisional managers to install carbon-free equipment that are currently unprofitable due to the world's lax attitude toward climate change, but will reduce future costs when carbon dioxide is taxed at a more reasonable level? Or is a genuine desire to do good a better interpretation of green incentives than the long-term perspective view? In the latter case, are these "green incentives" the object of intense communication to shareholders (suggesting vision 2) or a confidential policy (suggesting vision 3)?

In sum, we see that, as with individual consumers and investors, corporate "socially responsible behaviors" often carry much ambiguity as to their exact motivation.

(d) Do the data help us tell these theories apart?

Empirical studies often relate corporate profitability with socially responsible behavior. ${ }^{17}$ There seems to be, overall, no or a slightly positive correlation between socially responsible behavior and corporate returns (see Orlitzky et al. 2003, Margolis and Elfenbein 2007 and Margolis et al. 2007 for meta-analyses, Heal 2005 and Reinhardt et al. 2008 for further discussions). The interpretation of empirical analyses is, however, subject to three difficulties.

The first one concerns which CSR theory is being tested. We observed that visions 1 and 2 both predict a positive correlation between CSR and profits, ${ }^{18}$ while vision 3 predicts the reverse. In practice, CSR is likely to involve a mix of all three across the corporate sample, so it is unclear what specific channel is being tested.

The second difficulty pertains to the empirical strategy. On the causal-inference front, SRB and profitability are clearly both endogenous variables, raising the usual issue of what are the exogenous drivers (equivalently, what would be appropriate instruments) underlying the observed correlation patterns. If managers differ exogenously in their individual time horizons, for instance,

\footnotetext{
${ }^{17}$ A recent entry in this literature is Krüger (2009), who conducts event studies upon the announcement of ratings by KLD Research \& Analytics, a firm that provides environmental, social and governance (ESG) research for institutional investors. Stock prices fall on average by $1 \%$ within a week following a negative announcement. On the other hand, there does not seem to be an abnormal return after a positive announcement.

${ }^{18}$ At least up to a point. Barnea and Rubin (2006) argue that small amounts of CSR expenditures will raise profitability, while larger amounts will not.
} 
a positive correlation is to be expected (from vision 1). If they differ in the private value they derive from being associated with a firm known to act well toward its employees, consumers or the environment, then (from vision 3), one might expect a negative relationship. There could also be reverse causation, for instance if the most profitable firms are the best able to afford the cost of CSR or, as suggested by Margolis et al. (2007, 2009), have the most incentive to engage in it. ${ }^{19}$

An empirical strategy must also choose between operating performance and stock-market returns to measure "corporate returns". Both involve different problems. For operating performance (e.g. Return on Assets), the empirical challenge is the following: if one believes that CSR increases the mean profit by limiting rare disasters (vision 1), one needs very large samples to see that significantly in the data. Most studies look instead at stock returns. This raises the issue of whether CSR companies have different systematic risk exposures (either due to their resilience in periods of crisis or because they face a specific CSR risk factor), in which case they command different risk premia, and therefore have different expected returns. As Andries (2008) notes, "New laws and regulations are typically introduced when things go wrong... Socially responsible investors would simply be the ones with higher risk aversion to a deterioration of the "state of the world"".

Another issue is whether financial markets are still learning about CSR. Some people have in mind (implicitly or explicitly) that the stock market has been undervaluing the "true importance" of CSR, so that virtuous companies have positive abnormal returns (they keep surprising the market positively, in contradiction to market efficiency). An intermediate story is a "slow repricing", whereby environmental and social factors are gradually becoming recognized as relevant price factors for valuing a company; virtuous firms experience high returns during this recognition period, but should experience lower ones once the repricing is completed.

The third unknown involves extrapolation. Socially responsible investment has, so far, mostly been a marginal phenomenon, and there is no reason why profitability should remain the same as its prevalence increases. A key issue here is which types of socially responsible activities involve decreasing or, conversely, increasing. returns. For instance, a small number of environmentally concerned investors can always invest in the existing clean companies; it is therefore likely that CSR has had little impact on stock prices in the past. As SRI popularity increases, other firms may have to start incurring higher abatement costs in order to attract funding, depressing yields. ${ }^{20}$ Consistent with this idea of an increasing CSR discount, Andries (2008) finds, in the cross-section

\footnotetext{
${ }^{19}$ In his descriptive statistics, Krüger (2009) finds that "irresponsible companies" - defined as those for which KLD records more events of bad behavior - tend to have been less profitable in the past than responsible ones.

${ }^{20}$ In the long run, however, certain technologies (e.g., clean power more likely than reforestation) may benefit from economies of scale and learning-by-doing, bringing costs back down and yields up.
} 
of S\&P 500 firms and after controlling for industry and firm characteristics: (i) no significant relationship between asset returns and CSR over the 1991-2006 period; (ii) an emerging negative relationship for some criteria related to negative screening (tobacco, alcohol, gambling, nuclear power) over the more recent 2000-2006 period.

\subsection{Challenges for delegated philanthropy}

This section focuses on what may be the fastest-growing form of SRB (at least in terms of visibility), delegated philanthropy, and discusses some of the challenges ahead. Delegated philanthropy, as we noted, is a response to a widespread demand by stakeholders that firms they interact with be good corporate citizens. While it does not call into question traditional forms of governance, it does faces serious practical challenges, which will need to be confronted head on if this approach to CSR is to realize its full potential.

\section{(a) Free riding}

Socially responsible investment, the fair trade movement, and the desire to be employed by a socially responsible institution all involve a private provision of a public good. The temptation to free ride is substantial. We may be willing to pay our electricity $5 \%$ more if it is carbon-free, to sacrifice a bit on the yield on our savings, or to be paid a little less in order to feel good about our employer. But there are limits to such sacrifices. While people almost unanimously declare themselves willing to incur costs to improve the environment or promote development, attitudes change when things become more concrete. According to recent polls, $65 \%$ of the French people are opposed to the current, modest carbon tax, which they and all the candidates had embraced during the presidential campaign two years ago as a desirable national contribution to the reduction of global warming. It would be interesting to know how free riding will evolve if SRI becomes very popular and if this, through decreasing returns, significantly reduces the yield on socially responsible funds.

\section{(b) Information}

In order to choose a company to invest in, buy from or work for, investors, consumers and workers need information as to whether it really behaves prosocially. This raises three challenges:

- Data collection is itself a public good. It is therefore important that specialized rating agencies supply the required information to the public. Of course, these agencies may face inadequate incentives, as was demonstrated in the recent financial crisis, and there is ground to be vigilant. But the problem of reporting is not specific to this context, and we have to make with the need for delegation. 
- Different dimensions of good corporate citizenship need to be aggregated. Firms do well in some dimensions and poorly on others, so one of the challenges facing rating agencies is to find a methodology for adding then up into a synthetic index (or a small number thereof). How does one assess the closure of a plant that emits a lot of $\mathrm{CO} 2$, but provides jobs to a local community? Does one view nuclear power in terms of its definitely favorable impact against global warming, or of its long-lasting hazardous waste? Can a multinational offset some local environmental damage by financing a school, clinic or waste-treatment facility in the community?

- Should corporate social performance be assessed in absolute or relative terms? For example, an oil company may pollute a lot, but make substantial efforts to reduce its pollution and be "best in class". Relatedly, Landier and Nair (2008) have suggested including relative performance within the industry as a criterion for delineating socially responsible portfolios.

(c) Defining what is socially responsible

CSR inherits the strengths and weaknesses of the democratic process. As is well-known, politicians often tend to follow public opinion in order to pander to the electorate. ${ }^{21}$ Good public policy is therefore often conditioned by a proper understanding, or at least a lack of prejudice by voters in the relevant matter. A case in point is environmental policy. European politicians may impose a cost of over 1,000 Euros to economize one ton of carbon by subsidizing solar panels (most cost estimates range from 600 to 1,400 Euros), when they could have economized over 50 tons with the same money by buying out the carbon rights (the price of a ton in the EU's Emissions Trading System at the date of this writing is 15 euros). But, due to poor information or an imperfect understanding of the economics of the matter, or again the bias toward more visible, "symbolic" interventions introduced by voters' identity concerns, there is no electoral sanction, but actually an increase in popularity, attached to such moves.

Similarly, the challenge for a proper assessment of which firms are socially responsible is to disincentivize rating agencies and CEO's from pandering to their constituencies' (investors, consumers workers) biases. The same problem arises in many contexts. NGOs reselling confiscated ivory will be frowned upon by the public for behaving "immorally", even when this move lowers the price of ivory and thereby discourages poachers. A polluter may still be frowned upon after a tax on the pollutant is imposed at its Pigovian level (the polluter is then subject to "double taxation"). Regardless of their own attitude toward genetically modified organisms (GMO's), most experts would admit that popular attitudes on the subject are often driven by rather unscientific

\footnotetext{
${ }^{21}$ See, e.g., Maskin and Tirole (2004).
} 
arguments and based on little information. Finally, framing is bound to distort assessments: the choice of presenting a firm's rationale for locating a plant in a low-labor-cost country as "helping a poor country to develop" or "minimizing labor cost" is obviously not neutral.

(d) What kind of activism?

A much debated question for green or ethic funds is the nature of their action. Should they intervene in governance or more passively vote with their feet? In the latter case, should the fund engage in a dialog with the firm before excluding it from its portfolio?

Typically, green or ethic funds are informed (by lobbies, some multilateral organizations, etc.) of an "incident", i.e. a firm's potential misbehavior. The fund then "monitors" and enters a "dialog" or "engagement" with the firm to persuade it to alter its behavior, threatening a boycott if it does not comply. Some funds and NGOs prefer a "clean-hands" approach that does not involve any such dialog, by fear of being seen as soft on the infringer or of being led to a compromise that does not satisfy the socially responsible investors.

Another debate relates to the choice between positive and negative screening. Negative screening refers to the exclusion of unrepentant firms; positive screening consists in investing only in "best-in-class" corporations.

A third debate concerns whether the name of companies facing engagement, and not only those which end up excluded, should be published. There may be a good argument for not disclosing the names of firms involved in negotiations, so as to give them more of an incentive to alter their behavior. On the other hand, this may increase the risk of collusion or capture of the NGO or fund involved.

\section{Concluding thoughts}

While the invisible hand of the market and the more visible one of the state have been the objects of much research, we still know little about the decentralized correction of externalities and inequality.

This paper has argued that there are three possible understandings of corporate social responsibility: the adoption of a more long-term perspective, the delegated exercise of philanthropy on behalf of stakeholders, and insider-initiated corporate philanthropy. The latter two understandings build on individual social responsibility, which led us to review individual motivations for prosocial behavior. We saw that prosocial behavior by investors, consumers and workers is driven by a complex set of motives: intrinsic altruism, material incentives (defined by law and taxes) and social- or self-esteem concerns. These three motives are mutually interdependent, and both policymakers and social activists must have a good understanding of these interactions in order to properly harness people's desire to behave prosocially. 
We thus saw that the importance of social and self signaling concerns provides a powerful and cheap lever for certain types of interventions (up to a point) but makes others counterproductive, and that the pursuit of social and self esteem per se is a zero-sum game distorting actions towards the more visible.

While we have focused a fair amount of attention on image concerns, other "behavioral" aspects should also be added to the picture in order to augment our understanding of giving patterns. As with other choices such as retirement savings, default options (e.g., having to opt in or out) will be relevant, if only because they convey information as to what is expected by society. Should carbon offsets be included in airplane tickets with an opt-out option? Should a fixed percentage of paychecks be allocated to charities by default, or some fraction of $401(\mathrm{k})$ contribution directed to socially responsible funds, again with an opt-out option? Another interesting question is whether prosocial behavior is, like exercise and good hygiene, habit forming. Presumably, a belief in such virtuous habit formation underlies "compulsory volunteering" as prerequisite for most college admissions in the United States.

Research should obviously tackle another fundamental question: who, among the state, stakeholders and firms, is best placed to address market failures and inequality? Are their actions complement or substitutes? Could Public-Private-Parnerships maintain public involvement while harnessing private sector resources, efficiency and validation?

In this paper we purposely offered a somewhat cautious view of SRI and CSR, but our choice to work on this topic should be interpreted as a sign of optimism. Caring about the environment, the welfare of people in poor countries, and other good causes is a normal good. The richer our societies, the higher the demand for SRB. But one needs to lever altruism and signaling concerns in the right way, and this requires a good understanding of the psychology of giving and how it interacts with markets and other general-equilbrium forces. Economists, guided by the hands of Pigou and Smith, have so far paid insufficient attention to this topic. We hope that this paper, despite its modest scope, will encourage more research on this topic. 


\section{References}

[1] American International Group, Inc. (AIG) (2007) Corporate Responsibility Report, p. 4-5. Available at http://media.corporateir.net/media_files/irol/76/76115/AIG_CReport_0708.pdf

[2] Andries, M. (2008) "Social Responsibility and Asset Prices: Is there a Relationship?," mimeo, University of Chicago.

[3] Ariely, D., Bracha, A., and S. Meier (2009) "Doing Good or Doing Well? Image Motivation and Monetary Incentives in Behaving Prosocially," forthcoming, American Economic Review.

[4] Avlonas, N. (2009) "The Origins of Social Responsibility in Ancient Greece," mimeo, American College of Greece.

[5] Barnea, A. and Rubin, A. (2006) "Corporate Social Responsibility as a Conflict Between Shareholders," EFA 2006 Zurich Meetings.

[6] Baron, D. (2001) "Private Politics, Corporate Social Responsibility and Integrated Strategy," Journal of Economics and Management Strategy, 10:7-45.

[7] Bénabou, R. (2008a) "Ideology," Journal of the European Economic Association, April-May 2008 6(2-3), 321-352.

[8] Bénabou, R. (2008b) "Groupthink: Collective Delusions in Organizations and Markets," mimeo, Princeton University.

[9] Bénabou, R. and J. Tirole (2006a) "Incentives and Prosocial Behavior," American Economic Review, 96(5): 1652-1678.

[10] - (2006b) "Belief in a Just World and Redistributive Politics," Quarterly Journal of Economics, 121(2), 699-746.

[11] - (2007) "Identity, Morals and Taboos: Beliefs as Assets," CEPR Discussion Paper No. 6123, January.

[12] (2010) "Laws and Norms," mimeo.

[13] Besley, T., and M. Ghatak (2005) "Competition and Incentives with Motivated Agents," American Economic Review, 95(3): 616-636.

[14] - (2007) "Retailing Public Goods: The Economics of Corporate Social Responsibility," Journal of Public Economics, 91(9): 1645-1663.

[15] Brekke, K. and Nyborg, K. (2008) "Moral Hazard and Moral Motivation: Corporate Social Responsibility as Labor Market Screening," Resource and Energy Economics, 30(4), 509-526.

[16] Buraschi, A. and F. Cornelli (2003) "Donations", mimeo, London Business School.

[17] Carpenter, J. and C. Myers (2007) "Why Volunteer? Evidence on the Role of Altruism, Reputation, and Incentives", IZA Discussion Paper No. 302, September. 
[18] Cespa, G., and Cestone, G. (2007) "Corporate Social Responsibility and Managerial Entrenchment," ECGI - Finance Working Paper No. 157/2007.

[19] Dana, J., Kuang, J., and R. Weber (2007) "Exploiting Moral Wriggle Room: Experiments Demonstrating an Illusory Preference for Fairness," Economic Theory 33(1), 67-80.

[20] Dana, J., Cain, D. M., and Dawes, R. (2006) "What You Don't Know Won't Hurt Me: Costly (But Quiet) Exit in a Dictator Game," Organizational Behavior and Human Decision Processes, 100(2), 193-201.

[21] DellaVigna, S. List, J. and U. Malmendier (2009) "Testing for Altruism and Social Pressure in Charitable Giving," University of Chicago mimeo, October.

[22] Dewatripont, M., Jewitt, I. and J. Tirole (1999) "The Economics of Career Concerns. II: Applications to Missions in Organizations," Review of Economic Studies 66 (1): 199-217.

[23] Freeman, R. (1997) "Working for Nothing: The Supply of Volunteer Labor", Journal of Labor Economics, 15, 140-166.

[24] Friedman, M. (1970) "The Social Responsibility of Business is to Increase its Profits", New York Times Magazine, 13th September, p. 122-126.

[25] Funk, P. (2008) "Social Incentives and Voter Turnout: Evidence from the Swiss Mail Ballot System," forthcoming in the Journal of the European Economic Association.

[26] Geczy, C., Stambaugh, R., and D. Levin (2005) "Investing in Socially Responsible Mutual Funds," Working Paper, The Wharton School, October.

[27] Glazer, A. K. Konrad (1996) "A Signaling Explanation for Charity," American Economic Review, 86(4): 1019-28.

[28] Hamman, J., Weber, R., and G. Loewenstein (2009) "Self-Interest through Delegation: An Additional Rationale for the Principal-Agent Relationship," forthcoming in American Economic Review.

[29] Heal, G. (2005) "Corporate Social Responsibility - Economic and Financial Perspectives", Geneva Papers 30, 387-409.

[30] Holmström, B., and J. Tirole (1993) "Market Liquidity and Performance Monitoring," Journal of Political Economy, 101: 678-709.

[31] Hong, H., and M. Kacperczyk (2009) "The Price of Sin: The Effects of Social Norms on Markets," forthcoming, Journal of Financial Economics.

[32] Isherwood, C. (2007) "The Graffiti of the Philanthropic Class." The New York Times, December 2 .

[33] Jennings, M. (2006) The Seven Signs of Ethical Collapse: How To Spot Moral Meltdowns in Companies... Before It Is Too Late. New York, NY: St. Martins Press.

[34] Kitzmueller, M. (2008) "Economics and Corporate Social Responsibility," mimeo, European 
University Institute.

[35] Krüger, P. (2009) "Corporate Social Responsibility and the Board of Directors," mimeo, Toulouse School of Economics.

[36] Krueger, A. and A. Mas (2004) "Strikes, Scabs, and Tread Separations: Labor Strife and the Production of Defective Bridgestone/Firestone Tires," Journal of Political Economy, 112(2), 253-289.

[37] Lacetera, N. and M. Macis (2008) "Social Image Concerns and Pro-Social Behavior," IZA Discussion Paper 3771, October.

[38] Landier, A., and V. Nair (2008) Investing for Change : Profit from Responsible Investment, Oxford University Press.

[39] Margolis, J. and H. Elfenbein (2007) "Do Well by Doing Good? Don't Count on It," Social Responsibility. Special Issue on HBS Centennial. Harvard Business Review, 86(1): 19.

[40] — Elfenbein, H., and J. Walsh (2007) "Does It Pay to Be Good? A Meta-Analysis and Redirection of Research on the Relationship between Corporate Social and Financial Performance," Working Paper, Ross School of Business, University of Michigan.

[41] Maskin, E., and J. Tirole (2004) "The Politician and the Judge: Accountability in Government," American Economic Review, 94: 1034-1054.

[42] Mazar, N., Amir, O. and D. Ariely (2008) "The Dishonesty of Honest People: A Theory of Self-Concept Maintenance." Journal of Marketing Research, 45, 633-634.

[43] Monin, B. (2007). "Holier Than Me? Threatening Social Comparison in the Moral Domain." International Review of Social Psychology, 20(1): 53-68.

[44] Monin, B. and Miller, D. (2001). "Moral Credentials and the Expression of Prejudice," Journal of Personality and Social Psychology, 81(1), 33-43.

[45] Monin, B., Sawyer, P. .J., and Marquez, M. J. (2008) "The Rejection of Moral Rebels: Resenting those Who Do the Right Thing," Journal of Personality and Social Psychology, 95(1): 76-93.

[46] Orlitzky, M., Schmidt, F. and S. Rynes (2003) "Corporate Social and Financial Performance: A Meta-analysis", Organization Studies, 24(3), 403-441.

[47] Pigou, A. (1920) The Economics of Welfare, Macmillan and Co.: London.

[48] Reinhardt, F., Stavins, R., and Vietor, R. (2008) "Corporate Social Responsibility Through an Economic Lens," FEEM Working Paper No. 84.2008.

[49] Shavell, S. (2002) "Law versus Morality as Regulators of Conduct," American Law and Economics Review, 4(2): 227-257.

[50] Social Investment Forum (2007) Report on Socially Responsible Investing Trends in the U.S. Available at http://www.socialinvest.org/resources/research/ 